\title{
Face Masks for Noninvasive Ventilation: Fit, Excess Skin Hydration, and Pressure Ulcers
}

\author{
Marty O Visscher PhD, Cynthia C White MSc RRT-NPS AE-C FAARC, Jennifer M Jones, \\ Thomas Cahill MSc RRT-NPS FAARC, Donna C Jones PhD, and Brian S Pan MD
}

\begin{abstract}
BACKGROUND: Pressure ulcers (stages III and IV) are serious safety events (ie, never events). Healthcare institutions are no longer reimbursed for costs to care for affected patients. Medical devices are the leading cause of pediatric pressure ulcers. Face masks for noninvasive ventilation were associated with a high percentage of pressure ulcers at our institution. METHODS: A prospective cohort study investigated factors contributing to pressure ulcer development in $\mathbf{5 0}$ subjects using face masks for noninvasive ventilation. Color imaging, 3-dimensional surface imaging, and skin hydration measurements were used to identify early skin compromise and evaluate 3 interventions to reduce trauma: (1) a silicone foam dressing, (2) a water/polyethylene oxide hydrogel dressing, and (3) a flexible cloth mask. A novel mask fit technique was used to examine the impact of fit on the potential for skin compromise. RESULTS: Fifty subjects age $10.4 \pm 9.1$ y participated with color images for 22 , hydration for 34 , and mask fit analysis for 16 . Of these, $69 \%$ had diagnoses associated with craniofacial anomalies. Stage I pressure ulcers were the most common injury. Skin hydration difference was $317 \pm 29$ for sites with erythema versus $75 \pm 28$ for sites without erythema $(P<.05)$ and smallest for the cloth mask $(P<.05)$. Fit distance metrics differed for the nasal, oronasal, and face shield interfaces, with threshold distances being higher for the oronasal mask than the others $(P<.05)$. Areas of high contact were associated with skin erythema and pressure ulcers. CONCLUSIONS: This fit method is currently being utilized to select best-fit masks from available options, to identify the potential areas of increased tissue pressure, and to prevent skin injuries and their complications. Improvement of mask fit is an important priority for improving respiratory outcomes. Strategies to maintain normal skin hydration are important for protecting tissue integrity. Key words: pressure ulcer; skin compromise; erythema; face mask; noninvasive ventilation; skin hydration; color imaging; 3-dimensional imaging; mask fit; craniofacial anomaly. [Respir Care 2015;60(11):1536-1547. (C) 2015 Daedalus Enterprises]
\end{abstract}

\section{Introduction}

Pediatric patients are at risk for pressure ulcers due to immature skin, compromised perfusion, decreased mobility,

\footnotetext{
Dr Visscher and Ms Jones are affiliated with the Skin Sciences Program and Division of Plastic Surgery, Cincinnati Children's Hospital Medical Center, Cincinnati, Ohio. Ms White and Mr Cahill are affiliated with the Division of Respiratory Care, Cincinnati Children's Hospital Medical Center, Cincinnati, Ohio. Dr Jones and Mr Pan are affiliated with the Division of Plastic Surgery, Cincinnati Children's Hospital Medical Center, Cincinnati, Ohio.
}

This research was supported in part through a grant award from the "Prevention Above All" Program of MEDLINE Industries, Inc. altered neurological responsiveness, fluid retention, moisture, and medical devices. ${ }^{1}$ The morbidity and cost associated with treatment have led to stage III and IV pressure ulcers that occur in a hospital setting being classified as serious reportable events. ${ }^{2}$ Reductions in reimbursement for healthcare-

\footnotetext{
Dr Vissher has received research grant funding from Medline Industries. Ms White has disclosed a relationship with Philips Respironics. Mr Cahill has disclosed he was a member of the Carefusion Clinical Advisory Board. The other authors have disclosed no conflicts of interest.

Correspondence: Marty O Visscher PhD. Tel.: 513-803-0934. E-mail: marty.visscher@gmail.com.
}

DOI: $10.4187 /$ respcare. 04036 


\section{FACE MASKS FOR NIV}

acquired pressure ulcers were implemented in July of 2012 by the Centers for Medicare and Medicaid Services, ${ }^{3}$ extending to pediatric Medicaid services. More than $60 \%$ of pressure ulcers at our institution were associated with medical devices, including face masks for noninvasive ventilation (NIV). ${ }^{4}$ The majority of face mask ulcers were stage II injuries. This is a concern since stage II device-related ulcers have a greater tendency to progress to stage III and IV compared with pressure ulcers caused by other factors. ${ }^{5}$

\section{See the Related Editorial on Page 1708}

Pressure ulcers develop from applied pressure, resulting in periods of ischemia and damage to the epidermis ${ }^{6}$ and through to deeper layers of tissue. This is exacerbated by cycles of ischemia-reperfusion with formation of cytotoxic free radicals, but damage occurs after a single cycle with only $2 \mathrm{~h}$ of ischemia. ${ }^{7}$ Pressure ulcers may involve damage at all levels from the epidermis to the deep tissue and are classified as follows. ${ }^{8,9}$ Stage I is non-blanchable erythema that may be painful, soft, and warmer or cooler than adjacent tissue. Stage II is partial dermal loss (eg, shallow open ulcer or an intact blister). Stage III has dermal loss wherein subdermal elements are visualized. Stage IV pressure ulcers are full thickness tissue loss with exposed bone, tendon, or muscle. Unstageable ulcers are full thickness wounds covered by slough and/or eschar. Deep tissue injuries have grossly intact skin with underlying pressure-related tissue injury. ${ }^{10}$

Since stage II pressure ulcers involve epidermal blistering or tearing, those from devices may arise from mechanical stress combined with skin occlusion. Mask components in skin contact are frequently made of occlusive, non-breathable materials, such as plastic. Occlusion blocks normal transepidermal water loss. Over time, increased moisture can cause maceration and increased permeability to exogenous agents. ${ }^{11-13}$ Moist skin has a higher coefficient of friction, ${ }^{14,15}$ an effect that may enhance the effects of mechanical trauma. ${ }^{16}$ Skin with excess moisture is associated with more frequent and more severe ulcers (stage II). ${ }^{17}$

Importantly, proper face mask fit may be difficult, particularly in the pediatric population. ${ }^{18}$ Over $40 \%$ of pediatric patients with a face mask pressure ulcer had medical diagnoses associated with craniofacial anomalies. ${ }^{4}$ Often acting synergistically, poor fit creates localized pressure areas and leaks. Leaks often result in complications with NIV delivery equipment and negate the benefits of therapeutic pressure being delivered to the patient. Clinicians may further tighten the mask to achieve a seal that can compound the problem. Unfortunately, few interface options are available to offset pressure.

Identification of the earliest deviation from normal skin condition is essential, particularly for dark skinned patients who risk more severe injury where skin pigmenta-

\section{QUICK LOOK}

\section{Current knowledge}

Pediatric patients are at risk for pressure ulcers due to immature skin, compromised perfusion, decreased mobility, altered neurological responsiveness, fluid retention, moisture loss, and presence of medical devices. The morbidity and cost associated with treatment have led to stage III and IV pressure ulcers that occur in a hospital setting to be classified as serious reportable events. Pressure ulcers are commonly associated with interfaces used to facilitate noninvasive ventilation.

\section{What this paper contributes to our knowledge}

This fit method using 3-dimensional scans to select best-fit masks from available options, to identify the potential areas of increased tissue pressure and prevent skin injury and their complications, which resulted in reduced skin breakdown. Strategies to maintain normal skin hydration were also important for protecting tissue integrity.

tion may mask erythema. ${ }^{19,20}$ Deep tissue injuries (below the surface) are difficult to confirm with visual inspection. The presence of blanchable erythema signals the potential for pressure ulcer development.

We investigated factors contributing to pressure ulcer development in subjects using face masks for NIV in a prospective cohort study. We used high-resolution color imaging to identify early skin compromise and measured skin hydration to assess the impact of excess moisture due to occlusion. Three strategies to reduce tissue trauma from pressure and moisture were evaluated: (1) a silicone foam dressing, (2) a hydrogel dressing, and (3) a flexible cloth mask. Three-dimensional surface scanning was used on a subset of subjects to determine relative goodness of mask fit.

\section{Methods}

\section{Subjects}

The study was conducted from July 2010 to October 2013 among pediatric and adult in-patients. All patients using face masks for NIV were eligible to participate. Patients judged to be too medically unstable to tolerate mask removal and/or to complete study procedures were excluded. The Institutional Review Board approved the study, and parents or subjects (adults) provided written informed consent. The masks used by the study subjects were selected by the respiratory therapist based on ventilator support requirements. The therapist assessed mask positioning every $4 \mathrm{~h}$ per standard hospital protocol. 


\section{FACE MASKS FOR NIV}

\section{Study Design}

The 3-dimensional surface imaging and mask fit analysis were added later. Subjects had one or more assessments, depending upon their time of enrollment.

\section{Skin Evaluation}

All subjects were evaluated for the presence of facial skin compromise as follows: none, erythema (blanchable), stage I pressure ulcer, stage II pressure ulcer, stage III pressure ulcer, stage IV pressure ulcer, unstageable pressure ulcer, or deep tissue injury pressure ulcer. High-resolution color images were acquired under standardized conditions, fixed distance, and cross-polarization (Nikon D-90 camera, $60 \mathrm{~mm}$ Micro-Nikkor lens, Nikon R1 wireless close-up flash, Nikon) to visualize the sub-epidermal microvasculature ${ }^{21}$ and separated into $\mathrm{L}, \mathrm{a}^{*}$, and $\mathrm{b}^{*} \mathrm{im}-$ ages (ImageJ, National Institutes of Health, Bethesda, Maryland). ${ }^{22,23}$ Excess erythema was calculated from the red $\left(a^{*}\right)$ image as percentage of red pixels above the mean plus $1 \mathrm{SD}(\mu+\sigma)$ threshold. ${ }^{24}$

\section{Skin Hydration}

Skin hydration was measured at mask contact points at the nose bridge, upper and lower left and right cheeks, and chin immediately after removal and before moisture evaporation as capacitive reactance units (Dermal Phase Meter 9003, NOVA Technology, Gloucester, Massachusetts). Adjacent skin sites outside the mask served as normal skin controls. The hydration immediately after mask removal represents the moisture of normal skin respiration trapped between the skin surface and mask (ie, the moisture in contact with the skin when the mask is in place). ${ }^{25}$ Measurements were made at multiple times on some subjects. However, only data from the initial evaluation were used in the analysis to avoid confounding effects due to multiple measurements. The hydration data are reported only for sites with intact skin and without open wounds (ie, sites with no damage, blanchable erythema, stage I pressure ulcers, and deep tissue injuries). Stage II and III pressure ulcers are frequently open wounds. Consequently, skin hydration values are markedly higher than those for intact skin. Inclusion of these injuries would confound the interpretation of skin moisture due to mask occlusion.

\section{Intervention}

In accordance with our standard of care and at the discretion of the respiratory therapist, a subset of subjects with skin erythema or a pressure ulcer received one of 3 interventions depending on respiratory support: (1) a silicone foam dressing (Mepilex Lite) between the plastic mask and skin, (2) a 90\% water/10\% hydrogel dressing between the plastic mask and skin (Vigilon [Bard Medical Division, Covington, Georgia] or CarraDres [MEDLINE Industries, Mundelein, Illinois]), or (3) a cloth nasal mask (SleepWeaver, Circadiance, Export, Pennsylvania) instead of the plastic mask. The interventions were in place for $4 \mathrm{~h}$ before removal and measurement of skin hydration.

\section{3-Dimensional Imaging and Mask Fit Analysis}

Three-dimensional face scans were obtained with a portable light-based Artec MHT scanner (Artec Group, San Diego, California) (distance $60 \mathrm{~cm}$, resolution to $0.5 \mathrm{~mm}$, point accuracy $0.1 \mathrm{~mm}$, exposure time $0.2 \mathrm{~ms}$ ). Three commonly used masks were scanned: a nasal gel mask (Profile Lite, Philips Respironics, Murrysville, Pennsylvania), an oronasal mask (PerformaTrak, Philips Respironics), and a total face mask (PerforMax, Philips Respironics). The masks were fit to the subject face scans $(n=16)$ using 3-dimensional software (3dMD Vultus, 3dMD, Atlanta, Georgia) as follows: (1) align scan in profile view, (2) move mask over face scan, (3) register scans with mask as source and face as target, (4) select surface in contact with skin, (5) register points along the surface, and (6) measure distances between face and mask (Fig. 1). Mask fit was taken to be the mean distance $(\mathrm{mm})$ between the face and mask at about 20 points distributed along the surface. The relative goodness of fit is a mean of $0 \mathrm{~mm}$. Uniform fit is indicated by a low SD. A threshold of the mean plus $1 \mathrm{SD}$ $(\mu+\sigma)$ was used to identify areas of high contact. Positive distances $(\mathrm{mm})$ indicate that the mask is pushing into the face to achieve sufficient contact (Fig. 1, C and D), and negative values indicate the area is away from the face (ie, not in contact). It is important to note that the 3-dimensional scans cannot be reliably manipulated to simulate deformation of either the mask or the face when the mask is secured as in actual practice.

\section{Statistical Analysis}

Skin hydration data were analyzed using paired $t$ tests for under mask versus adjacent control skin (SPSS, SPSS, Chicago, Illinois) with significance at $P \leq .05$. The effects of masks and interventions were compared using univariate general linear models with site on the face as a covariate. Pairwise treatment comparisons were made with the method of Bonferroni to correct for multiple comparisons. Fit was determined by comparing 3 masks for mean, SD, and mean plus SD at specific points using univariate general linear models $(P<.05)$. Crosstab statistical procedures $\varphi$, Cramer's V, and contingency coefficient procedures were used to evaluate the effect of the presence or absence of a craniofacial anomaly on skin compromise classification. 


\section{FACE MASKS FOR NIV}

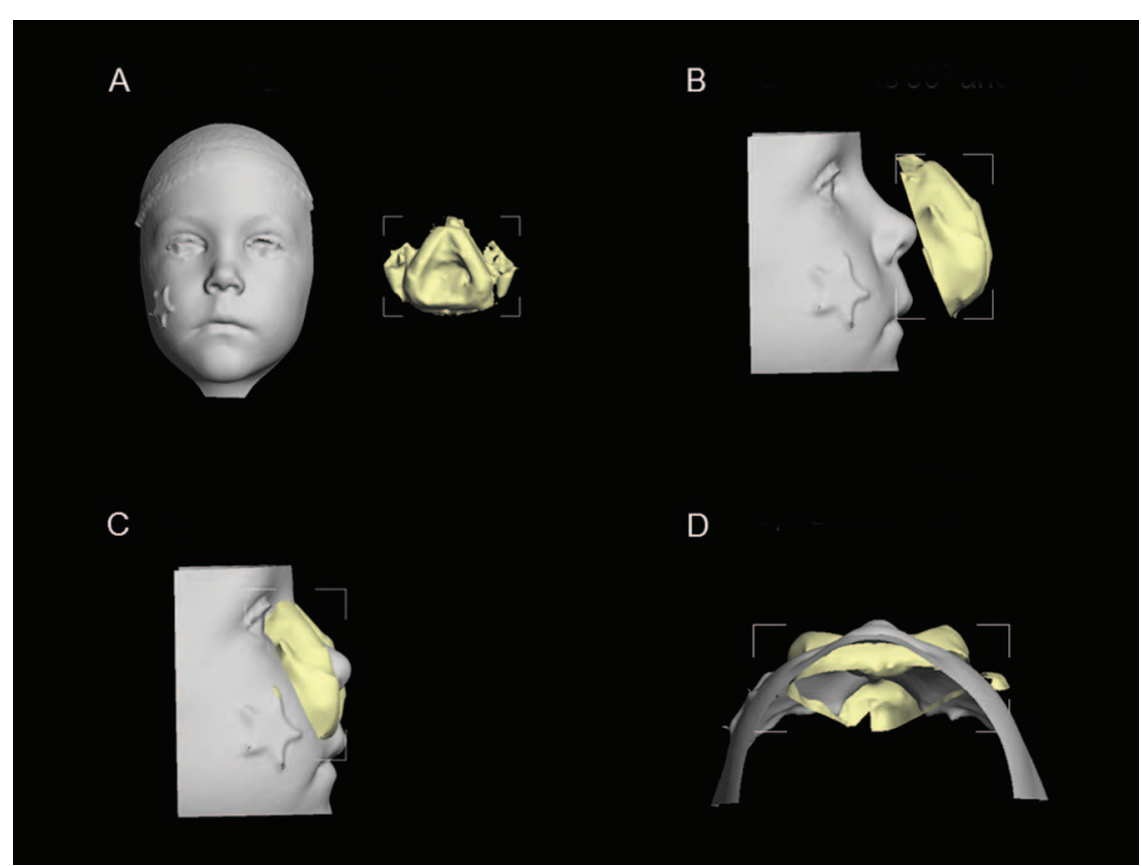

Fig. 1. Mask fit process. The mask fit process begins with 3-dimensional surface images of the subject's face (A). Three-dimensional scans are obtained of noninvasive mask types and sizes. Using the software (3dMD Vultus), the images are rotated, aligned (B), and registered to achieve contact between face and mask (C). Panel D shows a top down view of the mask fitted to the face. Portions of the mask come through the face to achieve fit, indicating that the mask pushes into the face.

\section{Results}

\section{Subjects}

Fifty female $(n=20)$ and male $(n=30)$ subjects age $10.4 \pm 9.1$ y (range 0.1-32.5) participated, with visual skin evaluation for all 50 subjects, color images for 22 subjects, hydration measurements for 34 subjects, and 3-dimensional scans with mask fit for 16 individuals. Skin condition was evaluated at multiple locations on the face, specifically the nose bridge, left and right upper cheeks, left and right lower cheeks, chin, and forehead. Table 1 indicates which measurements were made on each subject, skin condition, ventilator type, ventilator mode, pressures (total inspiratory positive airway pressure and total expiratory positive airway pressure), and mask. When skin compromise occurred at multiple sites, the site with the greatest damage is reported. Sixty-nine percent had diagnoses associated with craniofacial anomalies (eg, spinal muscular atrophy), and 9\% had abnormal facial dimensions (eg, cushingoid appearance) associated with therapeutic regimens.

\section{Skin Condition and Color Imaging}

Table 2 shows the type and frequency of skin compromise. Twenty-eight percent $(n=14)$ had no skin visible compromise. Stage I ulcers were the most common injury, followed by stage II, erythema, deep tissue injury, and stage III pressure ulcers. For 36 subjects with skin injury, there were 61 involved sites, most commonly at the nose bridge (39\%), followed by the left cheek (30\%), right cheek $(18 \%)$, forehead $(10 \%)$, and chin $(3 \%)$. The severity was greater for the nose bridge, with $50 \%$ being stage II, stage III, or deep tissue injuries. The cheek sites were limited to erythema (blanch) and stage I pressure ulcers. Skin compromise was of the more severe types (eg, stage III pressure ulcer and deep tissue injury) and appeared to be more prevalent among subjects with craniofacial anomalies (Fig. 2). However, group differences did not reach statistical significance as $P$ values were .06 for $\varphi$, Cramer's V, and contingency coefficient procedures.

Representative color images of 5 subjects are provided (Fig. 3). Figure 3A shows erythema on the nose immediately after mask removal in the morning after overnight NIV. Non-blanching erythema (stage I pressure ulcer) persisted throughout the day (mask not worn). The subject in Figure 3B had stage I pressure ulcers on the right cheek and forehead. Figure 3C shows a stage II forehead ulcer that developed during 1 night of mask usage. Figure 3, D and E, shows stage II and III pressure ulcers, respectively, on the nasal bridge.

To address the impact of pressures, we compared pressures for subjects grouped as follows: no skin compromise, erythema (blanchable), or pressure ulcer (any stage). 


\section{FACE MASKS For NIV}

Table 1. Skin Condition, Ventilator Type and Mode, Pressures, Mask Type, and Specific Measurements for Study Subjects by Presence or Absence of Craniofacial Anomaly

\begin{tabular}{|c|c|c|c|c|c|c|c|c|c|}
\hline ID no. & $\begin{array}{l}\text { Skin } \\
\text { Status }\end{array}$ & $\begin{array}{c}\text { Mask } \\
\text { Fit }\end{array}$ & $\begin{array}{l}\text { Color } \\
\text { Image }\end{array}$ & Hydration & Ventilator & $\begin{array}{l}\text { Ventilator } \\
\text { Mode }\end{array}$ & $\begin{array}{l}\text { Total } \\
\text { IPAP }\end{array}$ & $\begin{array}{l}\text { Total } \\
\text { EPAP }\end{array}$ & Mask \\
\hline \multicolumn{10}{|c|}{$\begin{array}{l}\text { With craniofacial } \\
\text { anomaly }\end{array}$} \\
\hline 5 & Stage II & & $\times$ & & Synchrony & $\mathrm{S} / \mathrm{T}$ & 10 & 4 & Respironics Profile light nasal mask \\
\hline 6 & Stage II & & $\times$ & & Focus & $\mathrm{S} / \mathrm{T}$ & 10 & 5 & Respironics Simplicity nasal mask \\
\hline 7 & None & $\times$ & $\times$ & $\times$ & Focus & $\mathrm{S} / \mathrm{T}$ & 20 & 8 & Sleepweaver cloth nasal mask \\
\hline 8 & Stage I & & & $\times$ & Synchrony & $\mathrm{S} / \mathrm{T}$ & 18 & 10 & Respironics PerformaTrak oronasal mask \\
\hline 9 & Stage I & & $\times$ & $\times$ & Focus & $\mathrm{S} / \mathrm{T}$ & 16 & 6 & Respironics PerformaTrak oronasal mask \\
\hline 12 & Stage II & & $\times$ & $\times$ & SERVO-i & NIV/PC & 18 & 8 & Respironics Profile light as oronasal mask \\
\hline 14 & Stage I & & $x$ & $\times$ & Focus & $\mathrm{S} / \mathrm{T}$ & 20 & 10 & Respironics PerformaTrak oronasal mask \\
\hline 15 & None & & & $x$ & Focus & $\mathrm{S} / \mathrm{T}$ & 14 & 8 & Sleepweaver cloth nasal mask \\
\hline 17 & Stage I & & & $\times$ & Focus & $\mathrm{S} / \mathrm{T}$ & 22 & 10 & Respironics PerformaTrak oronasal mask \\
\hline 18 & None & & & $\times$ & Focus & $\mathrm{S} / \mathrm{T}$ & 18 & 8 & Sleepweaver cloth nasal mask \\
\hline 19 & None & & & $\times$ & SERVO-i & NIV/PC & 14 & 6 & Respironics PerformaTrak oronasal mask \\
\hline 20 & Erythema & & & $\times$ & Synchrony & $\mathrm{S} / \mathrm{T}$ & 20 & 10 & Respironics PerformaTrak oronasal mask \\
\hline 21 & Erythema & & $\times$ & $\times$ & SERVO-i & NIV/PC & 24 & 10 & Respironics PerformaTrak oronasal mask \\
\hline 22 & None & & & $\times$ & Focus & & 20 & 8 & Sleepweaver cloth nasal mask \\
\hline 23 & Stage II & & & $\times$ & SERVO-i & NIV/PC & 21 & 8 & Respironics PerformaTrak oronasal mask \\
\hline 24 & Stage I & & $\times$ & $\times$ & Trilogy & $\mathrm{S} / \mathrm{T}$ & 30 & 10 & Respironics Profile light nasal \\
\hline 25 & Stage I & $\times$ & & $\times$ & SERVO-i & NIV/PC & 13 & 8 & Respironics PerformaTrak oronasal mask \\
\hline 26 & Stage II & & & $\times$ & V60 & $\mathrm{S} / \mathrm{T}$ & 21 & 7 & Respironics PerformaTrak oronasal mask \\
\hline 27 & None & & & $\times$ & Trilogy & $\mathrm{S} / \mathrm{T}$ & 22 & 6 & Sleepnet MiniMe nasal mask \\
\hline 28 & Stage II & & $\times$ & $\times$ & Trilogy & $\mathrm{S} / \mathrm{T}$ & 22 & 6 & Respironics Profile light nasal mask \\
\hline 29 & Stage II & $\times$ & & $\times$ & Trilogy & $\mathrm{S} / \mathrm{T}$ & 18 & 6 & Respironics PerformaTrak oronasal mask \\
\hline 30 & Stage I & & & $\times$ & Synchrony & $\mathrm{S} / \mathrm{T}$ & 19 & 9 & Sleepnet MiniMe nasal mask \\
\hline 34 & Stage III & & & $\times$ & Trilogy & $\mathrm{S} / \mathrm{T}$ & 24 & 6 & Respironics PerformaTrak oronasal mask \\
\hline 35 & None & $\times$ & & & SERVO-i & NIV/PC & 20 & 12 & Respironics Profile light as oronasal mask \\
\hline 36 & Stage II & $\times$ & & $\times$ & SERVO-i & $\mathrm{NIV} / \mathrm{PC}$ & 28 & 10 & Respironics PerformaTrak oronasal mask \\
\hline 40 & Stage II & & & & SERVO-i & NIV/PC & 20 & 8 & Respironics PerformaTrak oronasal mask \\
\hline 42 & Stage I & $\times$ & & & SERVO-i & NIV/PC & 18 & 8 & Respironics PerformaTrak oronasal mask \\
\hline 43 & Stage I & $\times$ & $\times$ & $\times$ & SERVO-i & NIV/PC & 16 & 6 & Respironics PerformaTrak oronasal mask \\
\hline 44 & Stage II & $\times$ & $\times$ & & SERVO-i & NIV/PC & 23 & 6 & Respironics med profile light as oronasal mask \\
\hline 45 & Stage II & $\times$ & $\times$ & & Trilogy & $\mathrm{S} / \mathrm{T}$ & 19 & 7 & Respironics Profile light nasal \\
\hline 46 & DTI & $\times$ & $\times$ & & Trilogy & $\mathrm{S} / \mathrm{T}$ & 18 & 10 & Respironics PerformaTrak oronasal mask \\
\hline 47 & None & $\times$ & $\times$ & & SERVO-i & NIV/PC & 16 & 6 & Respironics PerforMax Total face mask-XXS \\
\hline 48 & DTI & $\times$ & & & SERVO-i & NIV/PC & 22 & 10 & Respironics Profile light as oronasal mask \\
\hline 49 & Stage I & $\times$ & $\times$ & & Trilogy & $\mathrm{S} / \mathrm{T}$ & 20 & 5 & Fischer and Paykel Flex Fit nasal mask \\
\hline 50 & None & & & & Trilogy & $\mathrm{S} / \mathrm{T}$ & 20 & 6 & Resmed Bubble nasal mask \\
\hline \multicolumn{10}{|c|}{$\begin{array}{l}\text { Without craniofacial } \\
\text { anomaly }\end{array}$} \\
\hline 10 & Erythema & & $\times$ & $\times$ & Focus & $\mathrm{S} / \mathrm{T}$ & 16 & 6 & Sleepnet MiniMe nasal mask \\
\hline 11 & Stage I & & & $\times$ & Focus & $\mathrm{S} / \mathrm{T}$ & 26 & 20 & Respironics profile light nasal mask \\
\hline 13 & Erythema & & & $\times$ & V60 & $\mathrm{S} / \mathrm{T}$ & 14 & 8 & Respironics profile light nasal mask \\
\hline 16 & None & & & $\times$ & SERVO-i & NIV/PC & 24 & 10 & Respironics PerformaTrak oronasal mask \\
\hline 31 & None & & & $\times$ & SERVO-i & NIV/PC & 27 & 10 & Respironics PerformaTrak oronasal mask \\
\hline 33 & None & & & $\times$ & Focus & $\mathrm{S} / \mathrm{T}$ & 13 & 8 & Respironics Profile light nasal mask- medium \\
\hline 37 & Erythema & $\times$ & & $\times$ & Focus & $\mathrm{S} / \mathrm{T}$ & 22 & 8 & Sleepnet MiniMe nasal mask \\
\hline 38 & None & & & $\times$ & SERVO-i & NIV/PC & 17 & 8 & Respironics PerformaTrak oronasal mask \\
\hline 39 & Erythema & $\times$ & & $\times$ & SERVO-i & NIV/PC & 23 & 8 & Respironics PerformaTrak oronasal mask \\
\hline 41 & Stage II & $\times$ & & $\times$ & Trilogy & $\mathrm{S} / \mathrm{T}$ & 14 & 8 & Respironics Pediatric profile light nasal \\
\hline 1 & Erythema & & $\times$ & & NA & NA & NA & NA & NA \\
\hline 2 & Stage I & & $\times$ & & NA & NA & NA & NA & NA \\
\hline 3 & Stage I & & $\times$ & & NA & NA & NA & NA & NA \\
\hline 4 & Stage I & & $\times$ & & NA & NA & NA & NA & NA \\
\hline 32 & None & & & $\times$ & NA & NA & NA & NA & NA \\
\hline $\begin{array}{l}\text { IPAP }=\text { inspiratory } \\
\text { EPAP = expiratory } \\
\text { S/T }=\text { spontaneous } \\
\text { NIV = noninvasive } \\
\text { PC }=\text { pressure con } \\
\text { NA }=\text { not applicab }\end{array}$ & $\begin{array}{l}\text { airway pressure } \\
\text { airway pressure }\end{array}$ & & & & & & & & \\
\hline
\end{tabular}




\section{FACE MASKS FOR NIV}

Table 2. Type and Frequency of Skin Compromise for Study Population

\begin{tabular}{lc}
\hline \hline Extent of Skin Compromise & Subjects, $n(\%)$ \\
\hline None & $14(28)$ \\
Erythema, blanchable & $7(14)$ \\
Stage I & $14(28)$ \\
Stage II & $12(24)$ \\
Stage III & $1(2)$ \\
DTI & $2(4)$ \\
& \\
\hline DTI = deep tissue injury & \\
\hline
\end{tabular}

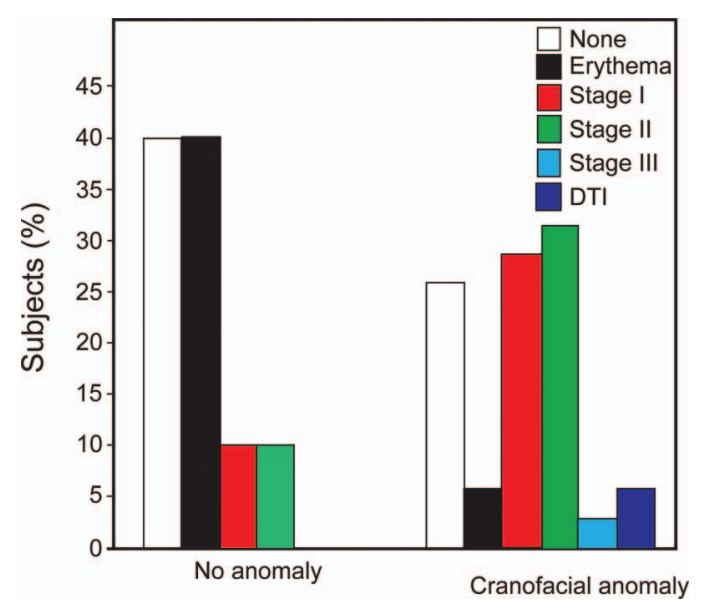

Fig. 2. Impact of craniofacial anomaly on face mask-related skin compromise. The skin compromise was of the more severe types (eg, stage III pressure ulcer and deep tissue injury [DTI]) among subjects with craniofacial anomalies compared with those without anomalies. However, the group differences did not reach statistical significance because $P$ values were .06 for $\varphi$, Cramer's V, and contingency coefficient procedures.

There were no differences in either inspiratory or expiratory positive airway pressures among the groups.

\section{Skin Hydration and Erythema}

Skin hydration was measured at 170 under mask sites and adjacent controls in 34 subjects for the plastic mask alone (no intervention, $n=90$ ), plastic masks plus 1 of 2 dressings $(n=18$ each), and the cloth mask intervention $(n=44)$ (Table 3$)$. Mean skin hydration under plastic masks (no intervention) was greater than normal skin $(P<.001)$. Hydration was higher than control when either dressing (silicone foam or hydrogel) was applied between the mask and skin $(P=.005$ and $P<.001$, respectively). In contrast, hydration under the cloth mask did not differ significantly from the control $(P=.14)$. The 2 dressings, cloth mask, and plastic mask alone were compared by using hydration differences from control (mask site - con- trol) (Table 3). The hydration difference was smaller for the cloth mask than the dressings and plastic mask alone $(P<.001)$. The hydration difference for the silicone dressing was smaller than the plastic mask alone and larger than the cloth mask $(P<.001)$. The SD values were high for both dressings, suggesting that the effects were highly variable. Visual erythema was scored as present or absent for 81 (of 170) sites. The hydration difference \pm SEM was $317 \pm 29$ for 40 sites with visible erythema versus $75 \pm 28$ for 41 sites without erythema $(P<.001)$.

\section{3-Dimensional Scans and Mask Fit}

The 16 mask fit subjects were $8.3 \pm 10.2$ y old $(0.1-$ $29.8 \mathrm{y})$ and weighed $23.9 \pm 19.5 \mathrm{~kg}(3.2-71.7 \mathrm{~kg})$. Of these, $69 \%$ had diagnoses associated with craniofacial anomalies, and $12 \%$ had abnormal facial dimensions due to treatment (eg, steroids). Six subjects had 11 pressure ulcers from the nasal or oronasal masks used in the fit analysis as follows: from the nasal mask, (1) stage II pressure ulcer on nasal bridge; (2) stage II on bridge and forehead; (3) stage II on forehead, stage I on bridge, left cheek, right cheek; and (4) deep tissue injury on bridge (used as full face mask); from the oronasal mask, (5) stage I pressure ulcer on left cheek and (6) stage II on the chin and deep tissue injury on the nasal bridge.

Analysis of the relative goodness of fit metrics showed differences among the nasal, oronasal, and total face masks (Table 4). SD values and thresholds $(\mu+\sigma)$ were higher for oronasal versus nasal and total face mask $(P<.05)$. The distances between mask and both cheeks were smaller for nasal versus oronasal and total face mask $(P<.05)$ (Fig. 4). The total face mask had the smallest distance at the bottom $(P<.05)$, due to negative values (away from the face) in some subjects. All 3 differed in the distance from the forehead, and nasal had the greatest value (eg, into the face) $(P<.05)$.

Images and fit data are shown in Figures 5, 6, and 7. Figure 5 shows a 5-month-old subject with a stage II pressure ulcer on the nose bridge while using the nasal mask. The mean distance was $3.0 \pm 4.1 \mathrm{~mm}$, indicating that it was pushing into the face. Compression would be expected on the forehead, with distances of 11.7, 12.2, and $12.0 \mathrm{~mm}$ (well above $\mu+\sigma$ ), the nose bridge $(3.1 \mathrm{~mm}$ ), and the lower corner $(3.7 \mathrm{~mm})$. The color image (Fig. 5A) shows areas of skin erythema at those points.

A 13-month-old subject had a deep tissue injury on the nose bridge when the nasal mask was used as a full face mask (Fig. 6). The facial scan with the mask in place is shown from the front (Fig. 6A) and from behind (from inside the face; Fig. 6B). The view from behind shows the mask coming through the face to achieve placement. The mean distance was $10.6 \pm 3.8 \mathrm{~mm}$. Point data suggest compression near the bottom on both cheeks (distances 


\section{FACE MASKS FOR NIV}

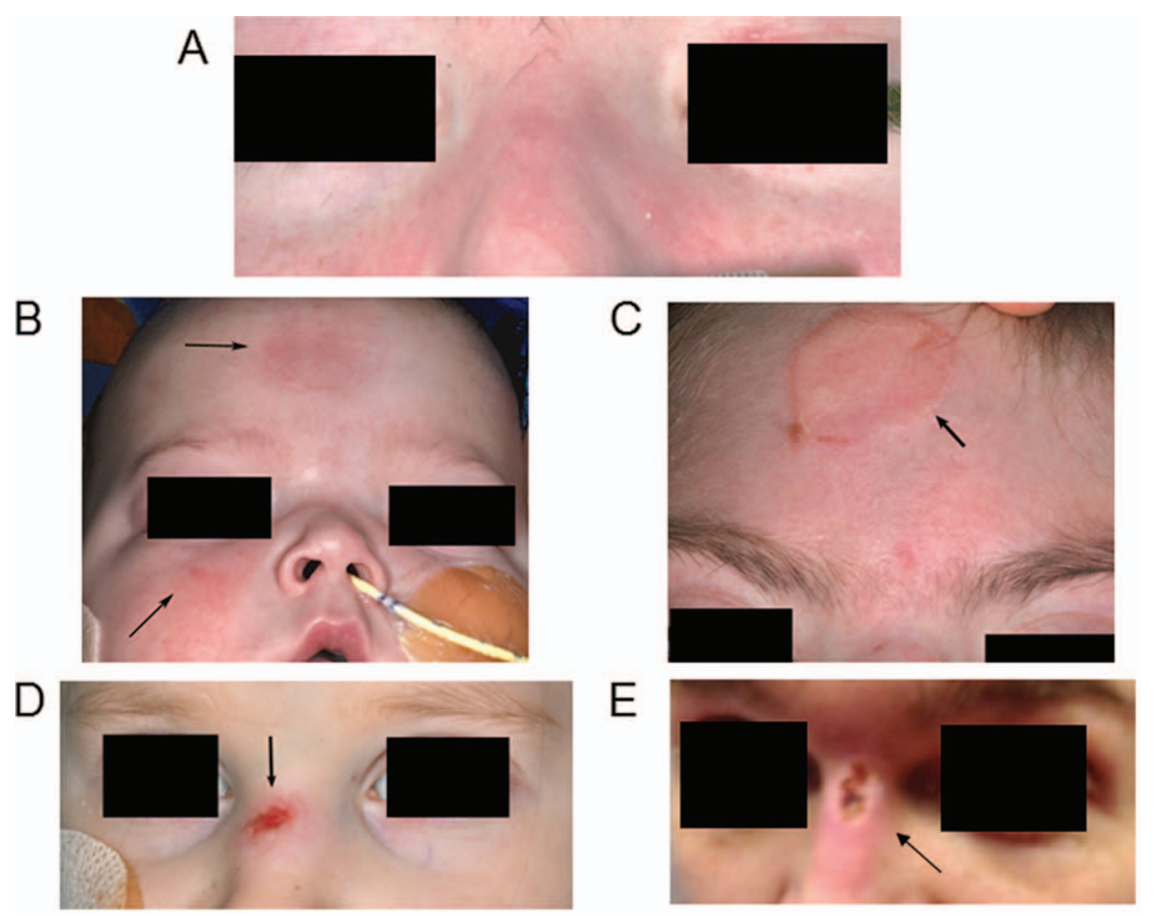

Fig. 3. Representative images of 5 subjects are shown. Panel A shows erythema on the nose immediately after the mask for overnight NIV was removed in the morning. Non-blanching erythema consistent with a stage I pressure ulcer persisted throughout the day. The subject in panel B has stage I pressure ulcers on the right cheek and forehead. Panel C shows a stage II ulcer on the forehead that developed over 1 night of wear. Panels D and E show stage II and stage III pressure ulcers, respectively, on the nasal bridge.

Table 3. Skin Hydration for Masks and Interventions

\begin{tabular}{|c|c|c|c|c|c|c|}
\hline Description & $n$ & Age, y & Under Mask, cru & $\begin{array}{c}\text { Adjacent Skin } \\
\text { Control, cru }\end{array}$ & $\begin{array}{c}P \\
\text { (mask vs control) }\end{array}$ & $\begin{array}{c}\text { Difference: } \\
\text { Mask - Control, cru }\end{array}$ \\
\hline Plastic mask only (no intervention) & 90 & $10.2 \pm 10.0$ & $417 \pm 211$ & $137 \pm 66$ & $<.001$ & $280 \pm 216$ \\
\hline Silicone foam dressing under plastic mask & 18 & $12.8 \pm 4.9$ & $295 \pm 166$ & $162 \pm 70$ & .005 & $133 \pm 174$ \\
\hline Hydrogel dressing under plastic mask & 18 & $5.3 \pm 7.3$ & $458 \pm 232$ & $127 \pm 23$ & $<.001$ & $331 \pm 218$ \\
\hline Cloth nasal mask & 44 & $13.6 \pm 6.4$ & $149 \pm 47$ & $173 \pm 114$ & .14 & $-24 \pm 107$ \\
\hline
\end{tabular}

16.0, 16.3, 16.6, and 17.8). The 9.2-mm distance may have been sufficient to cause a deep tissue injury.

An 18-y-old subject (Fig. 7) had a deep tissue injury on the bridge and a stage II pressure ulcer on the chin when using the oronasal mask. The mean distance was $-1.9 \mathrm{~mm}$, due to the forehead piece being away from the face, with a high SD value (Fig. 7C). Distances were 7.9, 8.0, and $8.3 \mathrm{~mm}$ for the bridge and left cheek points, respectively, constituting the greatest distances into the face. The distances were 4.4 and $4.1 \mathrm{~mm}$ along the bottom (chin).

\section{Discussion}

We used color imaging and skin hydration techniques to discern early tissue changes in subjects using face masks for NIV. We examined 3 strategies to reduce facial skin damage: (1) a silicone foam dressing, (2) a hydrogel dressing, and (3) a flexible cloth mask. We evaluated mask fit using 3-dimensional surface scans of the face and mask (Fig. 1) and compared fit parameters with tissue changes from imaging and visual inspection. Skin compromise of varying severity was observed in $72 \%$ of subjects. Areas of high mask contact were associated with skin erythema and pressure ulcers (Figs. 4-6). The distances into both cheeks were higher for the oronasal versus nasal mask (Table 4), suggesting that it poses a greater risk for tissue damage. Less than optimum mask fit may contribute to facial tissue injuries. Skin compromise may be more severe (eg, stage III or deep tissue injury) and frequency may be greater among patients with craniofacial anomalies. The 
FACE MASKS FOR NIV

Table 4. Mask Fit Data and Comparisons

\begin{tabular}{|c|c|c|c|c|c|}
\hline & \multicolumn{3}{|c|}{ Distance Metrics, mm } & \multirow{2}{*}{$P$} & \multirow{2}{*}{ Pairwise Comparison } \\
\hline & Nasal Mask & Oronasal Mask & Total Face Mask & & \\
\hline Mean & 4.4 & 4.1 & 4.6 & .86 & No differences \\
\hline SD & 2.9 & 7.1 & 3.8 & $<.001$ & Oronasal vs nasal, face \\
\hline Mean + SD & 7.3 & 11.2 & 8.4 & .01 & Oronasal vs nasal, face \\
\hline \multicolumn{6}{|l|}{ Local sites, mean } \\
\hline Forehead & 6.4 & -9.5 & 1.5 & $<.001$ & All different \\
\hline Bridge & 3.8 & 4.1 & NA & .82 & No differences \\
\hline Left lower corner & 3.4 & 4.6 & NA & .18 & No differences \\
\hline Right lower corner & 3.4 & 5.1 & NA & .040 & Nasal vs oronasal \\
\hline Left cheek & 5.2 & 11.1 & 8.6 & .003 & Nasal vs oronasal, face \\
\hline Right cheek & 5.3 & 11.5 & 8.1 & .002 & Oronasal vs nasal, face \\
\hline Bottom midpoint & 3.0 & 3.9 & 0.7 & .009 & Face vs nasal, oronasal \\
\hline
\end{tabular}

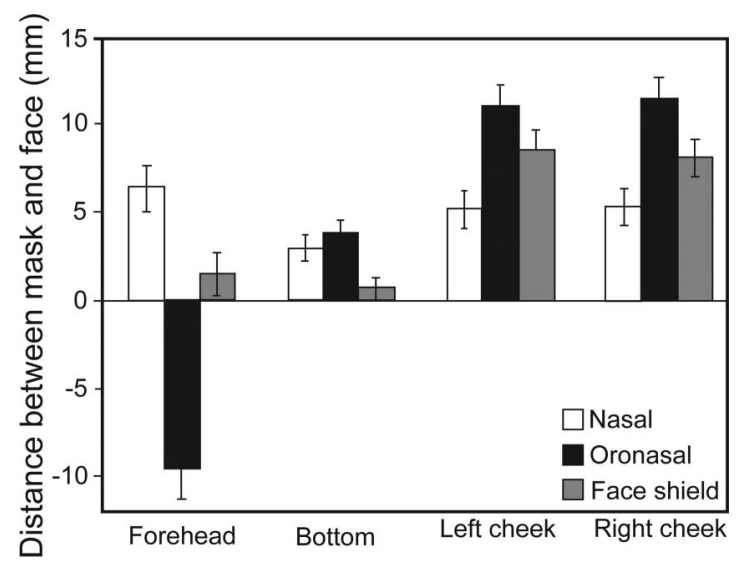

Fig. 4. The distances between mask and left and right cheeks were smaller for nasal versus oronasal and face shield $(P<.05)$. The total face mask had the smallest distance at the bottom $(P<.05)$, due to negative values (away from the face) in some subjects. All 3 differed in the distance from the forehead with nasal having the greatest value, ie, into the face at the forehead $(P<.05)$. Values are shown as mean \pm SD (error bars).

number without anomalies was small, however, thereby limiting conclusions regarding this condition. The frequency of craniofacial anomalies in the mask-wearing pediatric population has not yet been determined. The impact of facial features, craniofacial anomalies, and patient size (in relation to available masks) on skin damage/pressure ulcers has not been described, although mid-face hypoplasia as a result of long-term NIV therapy has been reported in pediatric patients. ${ }^{26,27}$ This underlying etiology should be considered when selecting masks for NIV. We observed more frequent and more severe skin compromise than previous reports of $49 \%$ with mostly transient or persistent erythema ${ }^{28}$ and $88 \%$ stage I pressure ulcers in neonates using masks. ${ }^{29}$

Our larger skin hydration differences were associated with visible erythema, as reported by others. ${ }^{30}$ Hydration was greater for erythema than normal skin and higher for stage I pressure ulcers than erythema. ${ }^{31}$ Since it differentiated tissue damage in dark skinned subjects, hydration measurement has been proposed for early detection of compromise. ${ }^{17}$ The cloth mask led to reduced hydration, and there was no erythema or tissue damage. Skin microclimate studies showed that increased humidity, increased skin temperature, and reduced permeability of materials in skin contact increased the risk of superficial pressure ulcers (ie, stage II). ${ }^{32,33}$ Our association of erythema with higher skin hydration is consistent with the predicted risk factors. The water vapor-permeable SleepWeaver mask resulted in decreased skin hydration relative to occlusive masks. Its effects on the skin microclimate probably explain the lack of skin erythema and pressure ulcers. Skin hydration was decreased with the silicone dressing interface, consistent with reduced injury when a silicone dressing was applied to the nose of infants on CPAP. ${ }^{34}$

Pressures exerted by masks were significantly higher at the nose bridge versus the cheeks in healthy adults. ${ }^{35}$ Thus, greater applied pressure may account for the higher frequency of the nasal stage II, stage III, and deep tissue injury pressure ulcers we observed. Clinically, strategies to minimize skin damage include alternating interface types/ designs, using proper fit techniques, reducing mask tightness, and applying spacers on the forehead to reduce pressure on the nose. ${ }^{36-38}$ Subjects with facial deformities were more difficult to fit, and subjects $\leq 2$-y-old used a custom mask due to the unavailability of acceptable commercial devices. ${ }^{18}$ Use of an oronasal mask was a significant risk factor for tissue injury among subjects $>18$ y old. ${ }^{39}$ Our results suggest that oronasal masks would be a risk factor in younger patients as well.

In the present study, more than half of the tissue injuries were in areas overlying bone (ie, nose bridge, forehead, and chin) with lesser ability to withstand pressure-related ischemia reperfusion injury. The presence of a craniofacial 


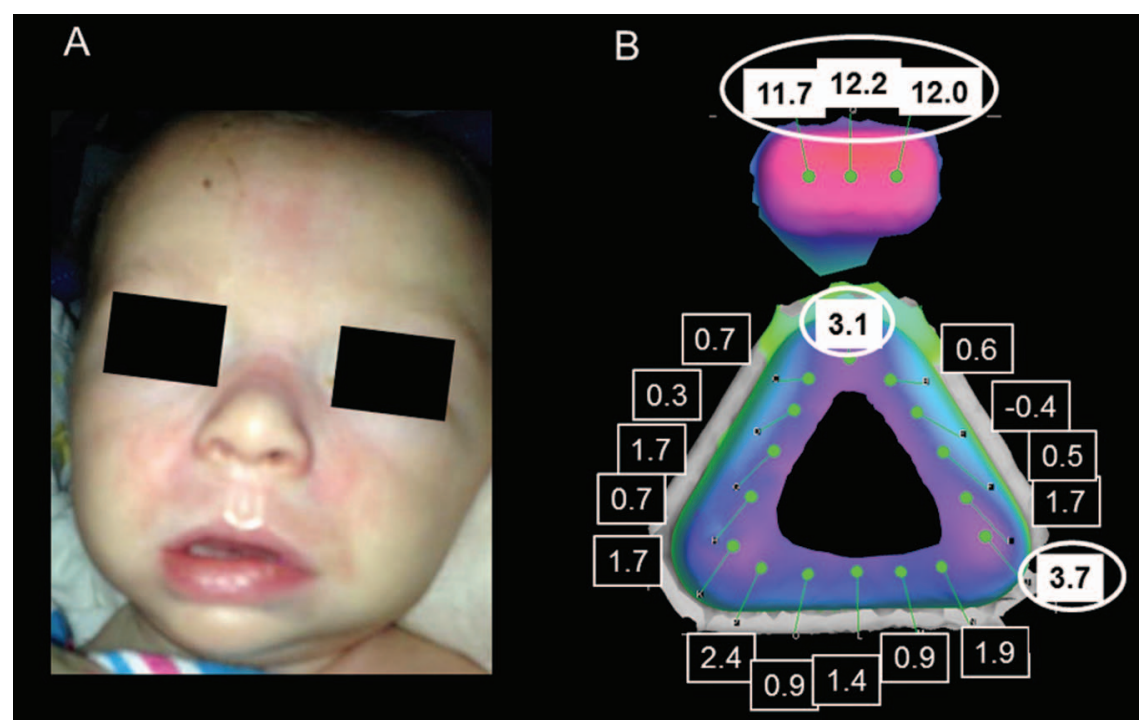

Fig. 5. A 5-month-old subject had a stage Il pressure ulcer on the nose bridge while using the nasal mask. The mean distance from the face to mask was $3.0 \pm 4.1 \mathrm{~mm}$, indicating that it was pushing into the face. Compression would be expected on the forehead, with distances of $11.7,12.2$, and $12.0 \mathrm{~mm}$, well above the mean and $\mu+\sigma$; the nose bridge $(3.1 \mathrm{~mm})$; and the lower corner $(3.7 \mathrm{~mm})$. The circled/shaded numbers $(B)$ indicate points of highest contact where tissue injury is expected. Panel A shows areas of skin erythema at those points.

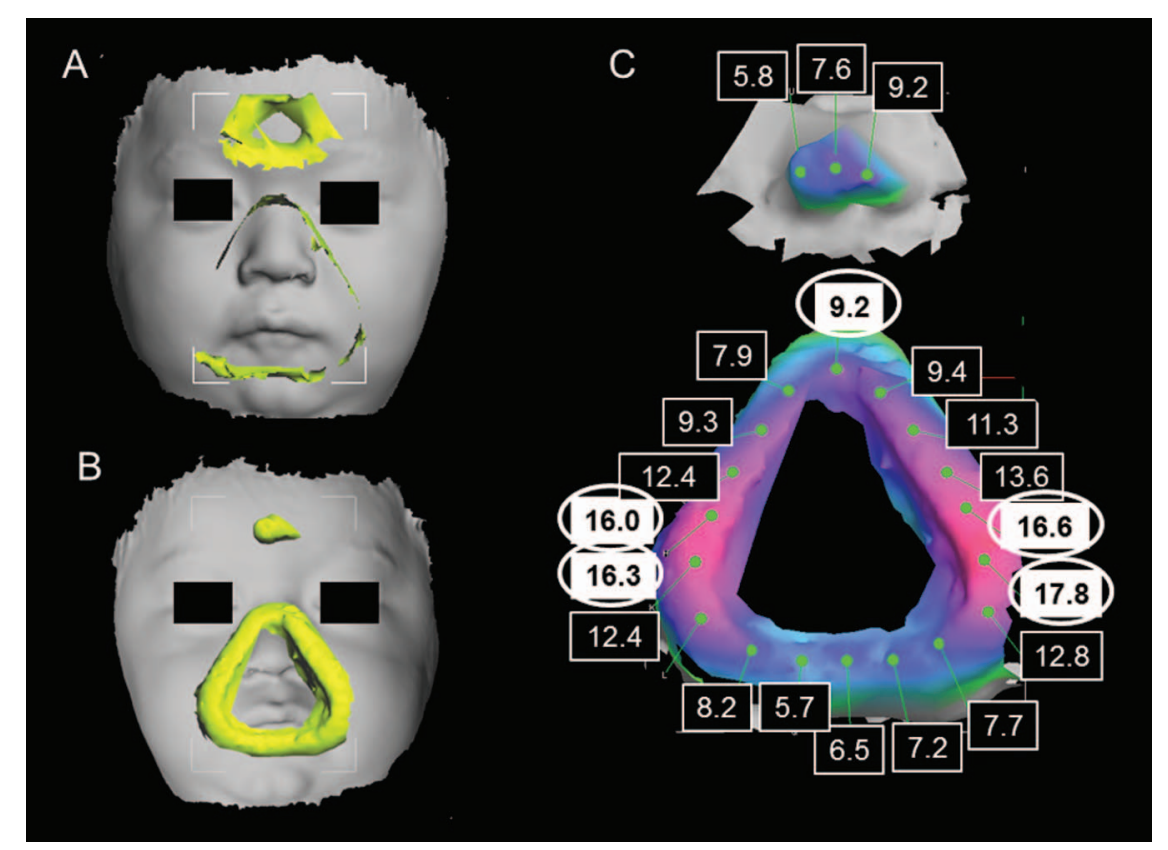

Fig. 6. A 13-month-old subject had a deep tissue injury on the nose bridge when a nasal mask was used as a full face mask. The facial scan with the mask in place is shown from the front $(A)$ and from behind $(B)$ (ie, as viewed from inside the 3-dimensional scan). The view from behind indicates that the mask is coming through the face to achieve placement. The mean fit distance was $10.6 \pm 3.8 \mathrm{~mm}$. C: Point data suggest compression near the bottom on both cheeks (distances 16.0, 16.3, 16.6, and 17.8 mm). The 9.2-mm distance may have been sufficient to cause a deep tissue injury.

anomaly alters facial shape, causing the bones to be in altered relative to normal. They include shorter facial height, changes in mandible length, greater interorbital distance (nasal, oral), and decreased cranial base size. ${ }^{40-42}$ Shape changes result in the mask being positioned over bony regions. Similarly, deficiencies in normal tissue behavior, such as poor perfusion, edema, and abnormal fat distribution, may cause abnormal pressure distribution over bony areas when the mask is worn. Bone position relative to the co-registered face mask could not be determined from our 


\section{FACE MASKS FOR NIV}

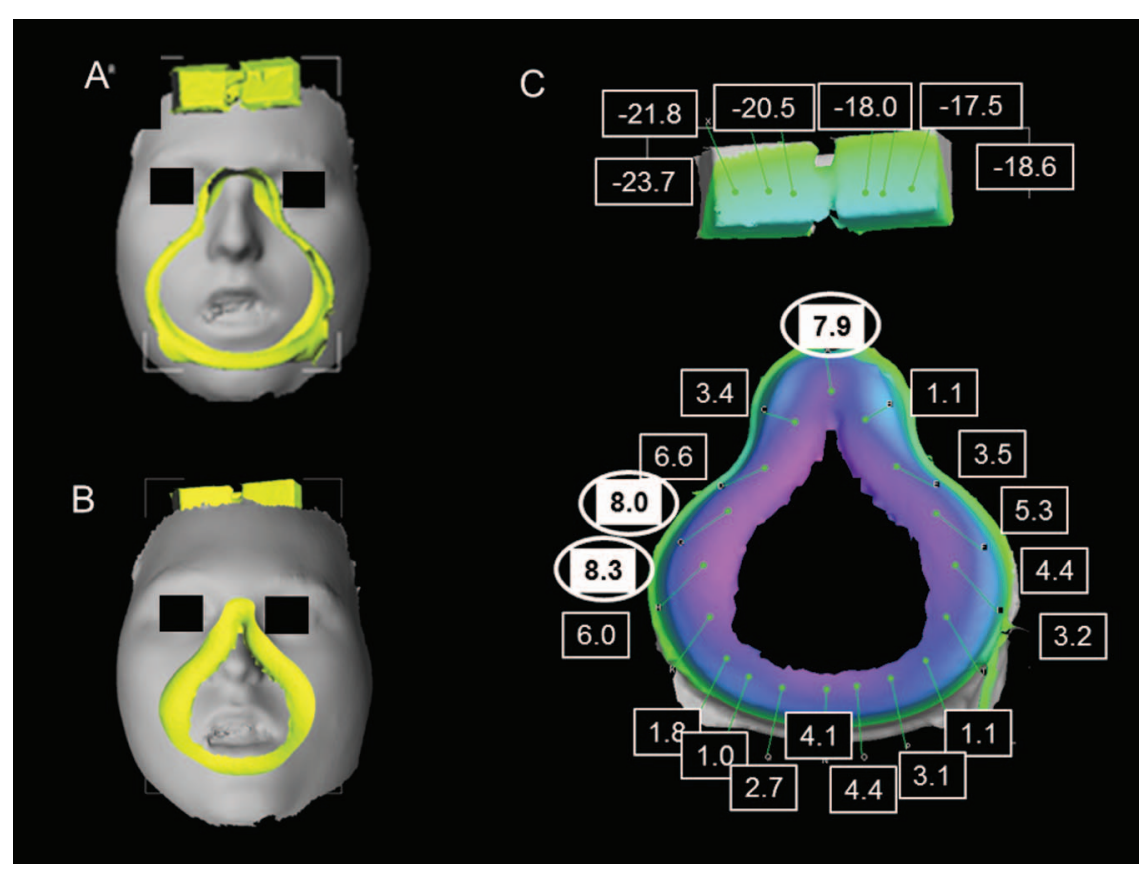

Fig. 7. An 18-y-old subject had a deep tissue injury on the bridge and a stage II pressure ulcer on the chin when using the oronasal mask. The mean distance was $-1.9 \mathrm{~mm}$, due to the forehead piece being away from the face, with a high SD (C). Distances were 7.9, 8.0, and $8.3 \mathrm{~mm}$ for the bridge and left cheek points, respectively, constituting the greatest distances into the face. The distances were 4.4 and $4.1 \mathrm{~mm}$ along the bottom (chin).

3-dimensional surface scans alone. However, 3-dimensional facial surface scans have been co-registered with cone-beam computed tomography data, ${ }^{43}$ and the method could be used to identify bone position in relation to tissue damage. Facial bone distances have been determined from correlations of magnetic resonance imaging data and frontal color photographs, suggesting that photographs could be used to judge bone location. ${ }^{44}$

Specific features of this study are important because they emphasize the utility and potential limitations of the results. It was descriptive of our population and may not be representative of other institutions. Inclusion of additional subjects to create a robust database is warranted. We did not examine the effects on skin over time from the start of NIV therapy or determine the time to skin injury. Both are important in understanding the impact of craniofacial anomalies on skin compromise and in deciding interventions. We did not have the capability to directly measure mask pressure applied to the tissue during wear. The cloth mask could not be scanned and analyzed for fit because it is a flexible interface. There were no injuries with this mask, and additional data are needed to confirm the result. Optimization of interventions to manage moisture is necessary. The distance $\mu+\sigma$ was used to approximate areas of tight fit and potential tissue damage. More data are needed to fully establish the relationship between fit distances and skin damage because only 6 subjects had an injury from the nasal, oronasal, or total face test masks.
We considered the scanned face to be inflexible (ie, if the mask came through the scan, it deformed the tissue). At the present time, neither the inherent flexibility of the face masks nor the biomechanical properties of the facial tissues can be incorporated into the fit procedures. The measured distances between mask and face are overcome in clinical practice by using mask flexibility and pliability of the mask surfaces (eg, cushions) as the mask is secured to ensure an appropriate seal. Ventilator tubing and patient position may also impact the forces experienced by facial tissue. Use of an intentional leak and/or a floating seal may decrease facial tissue pressure, but there are currently no ways to measure the effects and implement them to prevent/reduce skin compromise. Consequently, the model cannot yet simulate every face. Some facial tissue compression of the epidermis and dermis may be acceptable, but we do not know the "tolerance" limits where compression can occur without negatively affecting perfusion. The goal is to avoid altering perfusion and causing ischemiareperfusion injury and, ideally, to have the mask float on the skin with minimum pressure and compression.

Nevertheless, the major findings indicate that tissue injury from face masks for NIV may be significantly reduced if they provide optimum fit and are designed from materials that normalize skin hydration during wear. The mask fit method is being utilized to select masks from available options, to identify the potential areas of increased tissue pressure, and to prevent skin injury. There 


\section{FACE MASKS FOR NIV}

are opportunities for closing the knowledge gaps that currently exist regarding face masks for NIV and skin compromise in various patient populations. Further investigations are warranted to determine actual skin tissue pressures during mask wear, incorporate the effects of face mask flexibility and material properties, and develop interfaces that reduce injury.

\section{REFERENCES}

1. Schindler CA, Mikhailov TA, Fischer K, Lukasiewicz G, Kuhn EM, Duncan L. Skin integrity in critically ill and injured children. Am J Crit Care 2007;16(6):568-574.

2. National Quality Forum. (2008) Serious reportable events (SREs): transparency, accountability critical to reducing medical errors and harm. http://www.qualityforum.org/Publications/2008/10/Serious_ Reportable_Events.aspx. Accessed August 5, 2015.

3. Centers for Medicare and Medicaid Services (CMS), HHS. Medicaid program; payment adjustment for provider-preventable conditions including health care-acquired conditions. Final rule. Fed Regist 2011; 76(108):32816-32838.

4. Visscher M, King A, Nie AM, Schaffer P, Taylor T, Pruitt D, et al. A quality-improvement collaborative project to reduce pressure ulcers in PICUs. Pediatrics 2013;131(6):e1950-e1960.

5. Apold J, Rydrych D. Preventing device-related pressure ulcers: using data to guide statewide change. J Nurs Care Qual 2012;27(1):28-34.

6. Cornelissen LH, Bronneberg D, Bader DL, Baaijens FP, Oomens $\mathrm{CW}$. The transport profile of cytokines in epidermal equivalents subjected to mechanical loading. Ann Biomed Eng 2009;37(5):10071018.

7. Jiang LP, Tu Q, Wang Y, Zhang E. Ischemia-reperfusion injury-induced histological changes affecting early stage pressure ulcer development in a rat model. Ostomy Wound Manage 2011;57(2):55-60.

8. Bouten CV, Oomens CW, Baaijens FP, Bader DL. The etiology of pressure ulcers: skin deep or muscle bound? Arch Phys Med Rehabil 2003;84(4):616-619.

9. Stekelenburg A, Strijkers GJ, Parusel H, Bader DL, Nicolay K, Oomens CW. Role of ischemia and deformation in the onset of compression-induced deep tissue injury: MRI-based studies in a rat model. J Appl Physiol 2007;102(5):2002-2011.

10. Black J, Baharestani M, Cuddigan J, Dorner B, Edsberg L, Langemo D, et al. National Pressure Ulcer Advisory Panel's updated pressure ulcer staging system. Urol Nurs 2007;27(2):144-150, 156.

11. Kligman AM. Hydration injury to human skin. In: van der Valk $P$, Maibach HI, editors. The Irritant Contact Dermatitis Syndrome. Boca Raton, FL: CRC Press; 1996:187-194.

12. Lee JY, Effendy I, Maibach HI. Acute irritant contact dermatitis: recovery time in man. Contact Dermatitis 1997;36(6):285-290.

13. Ramsing DW, Agner T. Effect of water on experimentally irritated human skin. Br J Dermatol 1997;136(3):364-367.

14. Sivamani RK, Goodman J, Gitis NV, Maibach HI. Friction coefficient of skin in real-time. Skin Res Technol 2003;9(3):235-239.

15. Visscher MO, Chatterjee R, Ebel JP, LaRuffa AA, Hoath SB. Biomedical assessment and instrumental evaluation of healthy infant skin. Pediatr Dermatol 2002;19(6):473-481.

16. Zimmerer RE, Lawson KD, Calvert CJ. The effects of wearing diapers on skin. Pediatr Dermatol 1986;3(2):95-101.

17. Bates-Jensen BM, McCreath HE, Pongquan V. Subepidermal moisture is associated with early pressure ulcer damage in nursing home residents with dark skin tones: pilot findings. J Wound Ostomy Continence Nurs 2009;36(3):277-284.
18. Ramirez A, Delord V, Khirani S, Leroux K, Cassier S, Kadlub N, et al. Interfaces for long-term noninvasive positive pressure ventilation in children. Intensive Care Med 2012;38(4):655-662.

19. Barczak CA, Barnett RI, Childs EJ, Bosley LM. Fourth national pressure ulcer prevalence survey. Adv Wound Care 1997;10(4):18-26.

20. Henderson CT, Ayello EA, Sussman C, Leiby DM, Bennett MA, Dungog EF, et al. Draft definition of stage I pressure ulcers: inclusion of persons with darkly pigmented skin: NPUAP Task Force on Stage I Definition and Darkly Pigmented Skin. Adv Wound Care 1997;10(5):16-19.

21. O'Doherty J, Henricson J, Anderson C, Leahy MJ, Nilsson GE, Sjöberg F. Sub-epidermal imaging using polarized light spectroscopy for assessment of skin microcirculation. Skin Res Technol 2007;13(4):472-484.

22. Bahaskaran V, Konstantinides, K. Image and video compression standards: algorithms and architectures. Norwell, MA: Kluwer Academic Publishers; 1997.

23. Mark R, Billo, E. Application of digital image enhancement in rock art recording. Am Indian Rock Art 2002;28:121-128.

24. Canning J, Barford B, Sullivan D, Wickett R, Visscher M. Use of digital photography and image analysis techniques to quantify erythema in health care workers. Skin Res Technol 2009;15(1):24-34.

25. Visscher M, Hoath SB, Conroy E, Wickett RR. Effect of semipermeable membranes on skin barrier repair following tape stripping. Arch Dermatol Res 2001;293(10):491-499.

26. Li KK, Riley RW, Guilleminault C. An unreported risk in the use of home nasal continuous positive airway pressure and home nasal ventilation in children: mid-face hypoplasia. Chest 2000;117(3):916918.

27. Villa MP, Pagani J, Ambrosio R, Ronchetti R, Bernkopf E. Mid-face hypoplasia after long-term nasal ventilation. Am J Respir Crit Care Med 2002;166(8):1142-1143.

28. Fauroux B, Lavis JF, Nicot F, Picard A, Boelle PY, Clément A, et al. Facial side effects during noninvasive positive pressure ventilation in children. Intensive Care Med 2005;31(7):965-969.

29. Fischer C, Bertelle V, Hohlfeld J, Forcada-Guex M, StadelmannDiaw C, Tolsa JF. Nasal trauma due to continuous positive airway pressure in neonates. Arch Dis Child Fetal Neonatal Ed 2010;95(6): F447-F451.

30. Bates-Jensen BM, McCreath HE, Kono A, Apeles NC, Alessi C. Subepidermal moisture predicts erythema and stage 1 pressure ulcers in nursing home residents: a pilot study. J Am Geriatr Soc 2007; 55(8):1199-1205.

31. Bates-Jensen BM, McCreath HE, Pongquan V, Apeles NC. Subepidermal moisture differentiates erythema and stage I pressure ulcers in nursing home residents. Wound Repair Regen 2008;16(2):189197.

32. Yusuf S, Okuwa M, Shigeta Y, Dai M, Iuchi T, Rahman S, et al. Microclimate and development of pressure ulcers and superficial skin changes. Int Wound J 2015;12(1):40-46.

33. Gefen A. How do microclimate factors affect the risk for superficial pressure ulcers: a mathematical modeling study. J Tissue Viability 2011;20(3):81-88.

34. Günlemez A, Isken T, Gökalp AS, Türker G, Arisoy EA. Effect of silicon gel sheeting in nasal injury associated with nasal CPAP in preterm infants. Indian pediatrics 2010;47(3):265-267.

35. Munckton K, Ho KM, Dobb GJ, Das-Gupta M, Webb SA. The pressure effects of facemasks during noninvasive ventilation: a volunteer study. Anaesthesia 2007;62(11):1126-1131.

36. Nava $\mathrm{S}$, Navalesi $\mathrm{P}$, Gregoretti C. Interfaces and humidification for noninvasive mechanical ventilation. Respir Care 2009;54(1):71-84.

37. Newnam KM, McGrath JM, Salyer J, Estes T, Jallo N, Bass WT. A comparative effectiveness study of continuous positive airway pressure-related skin breakdown when using different nasal interfaces in 


\section{FACE MASKS FOR NIV}

the extremely low birth weight neonate. Appl Nurs Res 2015;28(1): 36-41.

38. Gregoretti C, Confalonieri M, Navalesi P, Squadrone V, Frigerio P, Beltrame F, et al. Evaluation of patient skin breakdown and comfort with a new face mask for non-invasive ventilation: a multi-center study. Intensive Care Med 2002;28(3):278-284.

39. Yamaguti WP, Moderno EV, Yamashita SY, Gomes TG, Maida AL, Kondo CS, et al. Treatment-related risk factors for development of skin breakdown in subjects with acute respiratory failure undergoing noninvasive ventilation or CPAP. Respir Care 2014;59(10):15301536.

40. Krimmel M, Kluba S, Breidt M, Bacher M, Müller-Hagedorn S, Dietz K, et al. Three-dimensional assessment of facial development in children with unilateral cleft lip with and without alveolar cleft. J Craniofac Surg 2013;24(1):313-316.
41. Silva Jesuino FA, Valladares-Neto J. Craniofacial morphological differences between Down syndrome and maxillary deficiency children. Eur J Orthod 2013;35(1):124-130.

42. Weinberg SM, Naidoo SD, Bardi KM, Brandon CA, Neiswanger K, Resick JM, et al. Face shape of unaffected parents with cleft affected offspring: combining three-dimensional surface imaging and geometric morphometrics. Orthod Craniofac Res 2009;12(4):271-281.

43. Nahm KY, Kim Y, Choi YS, Lee J, Kim SH, Nelson G. Accurate registration of cone-beam computed tomography scans to 3-dimensional facial photographs. Am J Orthod Dentofacial Orthop 2014; 145(2):256-264.

44. Sutherland K, Schwab RJ, Maislin G, Lee RW, Benedikstdsottir B, Pack AI, et al. Facial phenotyping by quantitative photography reflects craniofacial morphology measured on magnetic resonance imaging in Icelandic sleep apnea patients. Sleep 2014;37(5):959-968.

This article is approved for Continuing Respiratory Care Education credit. For information and to obtain your CRCE

(free to AARC members) visit www.rcjournal.com 